https://doi.org/10.48009/1_iis_2010_100-110

\title{
KNOWLEDGE-BASED SUPPLY CHAIN NETWORK: A SIMULATION APPLICATION DESIGN CONFIGURED WITH RADIO FREQUENCY IDENTIFICATION, FREIGHT TRAIN DISPATCH, AND CONTAINER SHIPMENTS
}

\author{
Andrew H. Chen, Soochow University, Taipei, Email: achensgc@yahoo.com \\ William A. Chen, University of California, Email: w1llsta@gmail.com \\ Christina E. Chen, University of California, Email: cechen@ucla.edu
}

\begin{abstract}
Owing to the transportation overcrowding in Southern California, a Knowledge-Based Supply Chain Network (KSCN) is envisioned to incorporate an On-Dock marine terminal, an emerging inland multi-modal freight hub, and a dedicated shuttle train to rapidly ship containers out of the marine terminal to an inland hub. To alleviate the full load of container shipments in Long Beach (LB), this study approaches Victorville, California $(90$ miles away from $L B)$ as the locale for the new inland freight hub. To accomplish its potential use of a maglev or high speed shuttle train, this study develops a KSCN through simulation and optimization, specifically by utilizing information flows as a platform for manipulating container shipments and data interactions. The purpose of this study is to present a shipping simulation model and an intelligent database using Radio Frequency Identification (RFID) and Automatic Equipment Identification (AEI) tag messages, and conclude that applying this essential freight simulation model can help configure the solutions and prevent the freight bottlenecks in the future.
\end{abstract}

Keywords: Train Simulation, RFID, AEI, Knowledge-Based System

Data Availability: For the simulation inputs, a data set of 25 actual train movements on the railways was obtained from The Burlington Northern Santa Fe (BNSF) Railroad Corporation. These freight dispatching schedules consisted of double-stack container train movements operating over a thirtyday period (mid-April to mid-May, 2007). These trains originated from the MAERSK On-Dock rail terminal at the Port of LB, were destined to eastern points of Colton Crossing, and finally were heading for Chicago. These raw data were not open to public due to confidentiality agreements.

\section{INTRODUCTION}

The Los Angeles (LA) region is home to a population of seventeen million. The LB port is the world's third largest container harbor. This port complex handles about $35 \%$ of all waterborne containers in the U.S. [2].

\section{Problems Addressed by the Study}

The economic benefits from the growth of container shipments constitute a dilemma to today's urban environments [8]. The challenging issues include port safety, congestion, economic impacts of the transportation system (e.g., mobility, accessibility, and reliability), and environmental quality [19].

The Southern California transportation system has been severely deteriorated by container shipments since 2000 [15]. Organizing and prioritizing freight flows and validating the suggested methodology are seen as preliminary steps toward problem solving among the shipping company stakeholders. For instance, at present time a better container shipment in LB port complex could be outlined as follows. (1) The vessels are designated to an On-Dock Rail Queue. (2) The containers are offloaded from the ships and are queuing near a yard gantry crane. (3) The containers are transported from the yard gantry area by loading them on the terminal tractor-chassis to the double-stack railcars (freight Unit Trains). A Unit Train may consist of 20 to 26 double-stack railcars, each railcar has 5 platforms. Each platform is able to carry two 40 foot containers. Each railcar can load a total of ten 40 foot containers. Therefore, a Unit Train may carry 200 to 260 pieces of 40 foot containers [21]. (4) The trains are pulled from the Intermodal On-Dock Rail Yards by the Pacific Harbor Switching Railroad and moved to an interchange point where the main line railway trains will "hook and haul". (5) The On-Dock railcars are sorted by destinations (e.g. Chicago or Houston) and Class 1 rail carriers of either Union Pacific Railroad Corporation (UPRR) or Burlington Northern Santa Fe Railroad Corporation. (6) A formed Unit Train is scheduled for pickup by a carrier locomotive, then dispatched, and finally on its way to the ultimate destinations (Texas, Midwest, or East Coast). 
A breakdown of commercial freight and passenger train deployments per peak day on the rail main lines in the LA basin for the Years of 2000, 2010, and 2025 was documented in a 2002 study sponsored by Southern California Association of Governments (SCAG) [12]. The SCAG's study requested an expansion of main-track territory (from two tracks to three tracks) to encompass the entire railroad in the Alameda Corridor and LA's most populated basin which appeared to be extremely unfeasible (because there was no land for expansion).

If the present trends continue between now and 2025, the port throughputs will exceed 36 million TEU (Twenty-Foot Equivalent Units). This volume translates into 91,000 local train and truck trips daily of To/From LB marine terminals and that almost triples the port complex volume of 34,000 at present. Therefore, the negative impacts and costs associated with absorbing trade-related growth from railcar shortages, labor lockouts, and truck blockages (trucks lined up outside marine terminals and Freeways I710, I-10) are absolutely expectable.

\section{Purpose of the Study}

To alleviate negative impacts of freight movements on the urban transportation while sustaining the region's economic vitality, the KSCN is envisioned to integrate long-term objectives that support the following components $[2,5]$ :

(1) An efficient marine terminal in LB (maximizing the use of On-Dock rail cargo loading),

(2) An inland multi-modal freight hub in Victorville (functioning as a new container control center),

(3) A maglev or high-speed shuttle train (dedicating short haul rail to connect the marine Terminal and the inland hub), and

(4) An information network system (including EDI, RFID, and a Knowledge-Based Data Center).

The first purpose of this study is to configure an initial phase of KSCN by designing a freight train simulation model and an intelligent database which can precisely serve as a base for the current and future logistics experiments. This model is able to emulate the regional supply chains, identify capacity gaps in the end-to-end freight deployment and dispatching process, and exploit the emerging inland hub of the new container yard. The second purpose of this study is to present a regional simulation model which is able to be appropriately converted and applied to other container port systems, for instance, Northeast Boston Port System.

\section{LIITERTATURE AND APPLICATION REVIEW}

\section{Simulation Model Applications}

A simulation model was a mathematical logical representation of a system which could be exercised in an experimental fashion on a digital computer [22]. Without a simulation analysis, the proposed system could be costly, unknown, and unsafe $[25,28,29]$.

On-Dock Model. The Mehlberg's Marine Terminal Server Model [20, 21] encompassed three wait queues of vessel berths, On-Dock intermodal rail, and gate operations. The On-Dock rail was the most time-sensitive model of freight flows which incorporated the intermodal shifts from vessels to double-stack railcars by the berth. This application obliged sufficient space as a rail buffer to consolidate a Unit Train in the port area. With the advent of Mehlberg's model, the On-Dock loading operation became significantly more efficient than ever. His model has been implemented in numerous highprofile harbors $[20,21]$.

Rail Dispatching Model. The Leachman's rail dispatching model had been progressively developed to plan track capacity and analyze rail operations in the Los Angeles trade corridor region and the Bay Area light rail region $[9,10,11,12]$. The model was utilized extensively during the period $1983-1999$ in connection with the planning, analysis and justification of the Alameda Consolidated Rail Corridor [26].

The SCAG had as well sponsored numerous studies of rail operations between Los Angeles and the Ports of Long Beach using various scenarios under numerous routing alternatives [13].

Lately, the California State University, Long Beach, sponsored a study of main line rail traffic in the entire Los Angeles Basin (east to Las Vegas) using a similar simulation model $[4,17]$. The changes and additions to rail track and train routings in the LA Basin which were crucial to accommodate 2010 and 2025 traffic forecasts were identified by the Chen's simulator [4]. Thus the CSULB's study on train operations was simulated in a similar way as this study, and those train operations [4] were extracted into this current KSCN simulation model.

\section{Real Time Accessibility Using EDI and RFID}

Mallon's Agile Port System (APS) used data flows as a surrogate to represent physical movements and key 
control elements in the supply chain processes [15]. $\mathrm{He}$ inquired to define information technology architecture by capturing a few key attributes, an XML database, a web 2.0 portal, and a Data Center. His research team used such data from the military Electronic Data Interchange (EDI) messages and other message formats, such as rail Car Location Messages (CLM), as a medium in combination with Radio Frequency Identification (RFID) tags and bar code readers to identify containers movements through the APS $[6,7,16]$.

Both the simulation model and the web database are essential to numerous subsequent studies and applications. The challenges to the accuracy and preciseness of statistics and simulations appear to leave extensive work to be done by current researchers and industry stakeholders [4].

\section{RESEARCH FRAMEWORK AND DESIGN}

This paper's framework consisted of four sections. This study (1) began with blueprinting a freight train dispatching simulation model by exhibiting the train specifications, track utilization, queuing optimization, and simulation algorithms. Secondly, (2) we used the data analysis to convert actual shipment EDI data and other train data collected from the RFID/AEI data tags into an intelligent database. These data could be accessed from the simulation model. Then, this study (3) conducted an experiment by using a dispatching simulation model and real data to exhibit the outputs and performance. Finally, we (4) concluded with flow time validation, implications for the future forecasts, and a conversion option which could be used by other Container Port Systems.

\section{DESIGN OF FREIGHT TRAIN DISPATCHING MODEL}

\section{Regional Rail Dispatching Simulation Model}

A model is a logical description of how a system and process behave. This rail dispatching simulation model utilized the discrete-event simulation methodology and the AWESIM Simulation Language [23].

This simulation design emphasized the freight movements in the LA basin and surveyed the dispatching data in main line train operations between Long Beach Junction (a junction point located at south of the Alameda Corridor and Port of Long Beach) and Colton Crossing (in San Bernardino County). The focused rail data and operations included the rail lines traversed by BNSF and UPRR trains between these points as well as METROLINKowned lines. Figure 1 provides an overview map of this rail dispatching simulation routes in the simulation model.

\section{<insert Figure 1 here>}

\section{Dispatching Algorithm, Entities, Arrivals, Departures, Activities, and Queues}

The design logic of simulation model was briefly summarized as follows [13]:

- An event calendar was maintained within the simulation engine containing events for the trains ready to depart and arrive at the end points of track segments.

- When a central dispatching simulation engine was called to process an event activity, it decided whether the train should continue to move (i.e., take possession of additional track resources) or begin to decelerate to a stop.

- A train began decelerating to a stop either when the necessary track segment or junction resource had been awarded to other trains, or a continuation of its movement would cause a deadlock.

- If a train stopped, this train was placed in a queue to wait for an available track resource to be released.

- If the central dispatching simulation engine decided to move a train, the algorithm determined the followings:

(1) The distance that the train would travel within the awarded track resource.

(2) The time of travel over the track resource that accounted for change-of-speed points.

(3) The successor track resources that could be possessed by this train.

- The central dispatching simulation engine assigned a track resource to a train, and scheduled a "resource-free" event when a train no longer needed it during the movement.

- When a resource-free event was encountered, all the trains in the queue were checked to see whether this released resource could trigger a movement from one of the stopped trains.

- The triggered train in the queue was the one with the highest priority and longest waiting time. Its movement would be determined by the central dispatching algorithm in the same manner as mentioned above.

- Finally, if a train arrived at its destination terminal, statistics concerning the train movement would be recorded, and the train would be terminated from the system. 
- When the simulation finished, the summary outputs would be generated according to the average delay time by trains, transit time by train types, and variation reports by origin-destination pairs.

\section{Specifications of Input Files}

The input file records were in the form of fixedformat texts that could be extracted from the intelligent database. Input record specifications for the simulation model were outlined as follows [3]:

(1) The Track Network Data - This physical rail network was represented by two resources of track segments and junction switches. Each segment of track had a specified uniform speed limit. Parallel tracks were distinct segments. Maximum speed over junction switches also was specified in the files.

(2) The Train Type Data - These records specified the train length, maximum speed, and acceleration and deceleration rates for train types.

(3) The Train Schedule Data - These schedules specified the train type, origin, and destination for each train ID. They also specified interarrival time.

Data appearing in these files were automatically mapped into simulation input formats by codes added to the simulation engine. For the purposes of this study, input records for the Track Network and Train Types were considered fixed and internal (collected from the on-site surveys) to the simulation model.

The Train Schedule data for all main line rail movements in the Los Angeles Basin were developed by Leachman and Associates while performing the other researches for the Southern California Association of Governments [12] and California State University, Long Beach [15]. These schedules included all main line tracks and movements from the south end of the LB junction to Colton Crossing via UPRR and BNSF. METROLINK lines utilized by UPRR and BNSF trains also were included.

\section{Specifications of Output Files}

The output records of the train dispatching simulation model consisted of text files of statistics by train ID and by location. An output summary by train ID was outlined as follows [3]:

(1) Transit Time - mean, standard deviation, minimum, and maximum.
(2) Delay Time - mean, standard deviation, minimum, and maximum.

(3) Mileage - mean, standard deviation, minimum, and maximum.

(4) Size of Queue of waiting trains at origin station mean and maximum.

(5) Wait Time at origin station - mean over trains that waited.

(6) Probability that a train waited at origin station fraction of simulated trains that were delayed.

Another output summary by location (node) was outlined as follows:

(1) Probability - Fraction of a simulated train that stopped at the specific location.

(2) Average Wait Time - the duration when a train stopped.

\section{DATA ANALYSIS}

Simulation performance measurement requires data. In the following, the required simulation data sets and the Input and Output files were obtained from the industry stakeholder BNSF, Ft. Worth, TX. Only the simulation related data sets would be illustrated with their definitions in this study.

\section{Universal Machine Language Equipment Register}

In order to provide the rail movement simulation, specific supporting data were required. These data were maintained by the Business Services Division Interline Service of the Association of American Railroads, RAILINC. The records were formatted in the UMLER file (Universal Machine Language Equipment Register). Specific excerpts from this extremely large UMLER file were required for the use of train length calculation. This UMLER file layout containing certain required data for all Intermodal equipments in North America are shown in the Table 1 [2].

\section{<insert Table 1 here〉}

\section{Radio Frequency Identification and Automated Equipment Identification}

The RFID comprised two components of tags which were attached to the containers or pallets and readers for reading the identity of the tags. The RFID was essential to secure the contents and location accessibility of containers or pallets, and reduce the risk of hazardous material imports. 
Among RFID applications, the North America freight trains used AEI to provide information about a railcar passing a certain point in the tracks of the railroad system. The AEI data were generated by the passive electronic tags affixed to the railcars (one for each side) and by the passing electronic reader antennae located at the points of railroads. The AEI data were critical for the management of an efficient rail schedule and asset management, e.g., railcar ID, length of car, and axle patterns. The data collected were transmitted with a date/time stamp to the railroad company. The electronic reader antennae located at the points of railroads were used when tracking a train through certain areas to monitor train movement progress and determine delays and impediments to the train transit [2]. Table 2 describes an AEI record example and each field definition.

\section{<insert Table 2 here>}

\section{Database Design}

The rail carriers provided real-time data for database analysis and design. However, such transmitted EDI records had layouts which were not in consonance with the relational database definitions. The RFID and AEI records were also not consistently related to EDI structure. It was incumbent upon the database administrator's responsibility to consolidate all proposed EDI sets and RFID/AEI records by using the skills of comprehensive relationships and easy accessibility. In this study, all EDI sets had been logically remodeled to define the primary keys for identifying unique attributes in each entity, add new attributes for sequentially ordering the looping entities, or add new attributes inherited from the leading entity of the loop. This study further defined the foreign keys by linking the identical attributes such as container number between entities and building parent-child relationships. The specific simulation input data could be extracted by writing sophisticated SQL queries to join multiple tables and form a new record for the input requirements [2].

\section{SIMULATION RUNS}

A data set of 25 actual BNSF double-stack container train movements operating over a thirty-day period (mid-April to mid-May, 2007) was obtained from the railroad AEI tags and receivers. This data set included AEI actual passing times at selected points from the BNSF/MAERSK container train movements. These trains originated at the MAERSK On-Dock rail terminal at the Port of Long Beach and were destined to eastern point, Chicago. Referring to
Figure 1, the route of these train movements coincided with the simulation rail simulation network from Long Beach Junction to Colton Crossing (81.5 miles from Long Beach Junction).

The rail dispatching simulation model included not only these freight train movements but also all others train movements operating over these main lines. These other movements included passenger trains (AMTRAK intercity and METROLINK commuter), other Intermodal freight trains, bulk Unit Trains, and carload freight trains [12].

\section{Input Data for Simulation}

The identical start schedules from Long Beach Junction were extracted from 25 actual BNSF trains. They were used to create simulation entities, queues, and routing activities. The initial simulation input data consisted of Train ID, Train Length, Container Number, and Start Date/Time from Origin. The other data for supporting the simulation runs were retrieved from the intelligent KSCN database and UMLER file.

\section{Computer Execution of Simulation Jobs}

This simulation model was applicable to virtually match the main line rail network. For the current Los Angeles Basin dispatching simulation model, the computer run time to emulate one month's train movements was about 60 minutes (the data conversion and database creation time were not included) on a Windows workstation using a Pentium CPU with adequate memory.

\section{Test Inspection of Outliers}

The following statistics were computed from the actual movements, Long Beach Junction - Colton Crossing: mean transit time, standard deviation of transit time, minimum transit time, and maximum transit time. These data were used to compare to the same statistics from the simulated train movements. Table 3 displays the summary.

\section{<insert Table 3 here}

As seen in Table 3, all the statistics on the actual transit times were somewhat greater than the corresponding statistics on simulated movements. Therefore, a train-by-train review of the EDI and AEI passing times of the actual train movements was undertaken, and two anomalies were discovered. The Train \#19 experienced a three-hour delay between Hobart and Pico Rivera, and The Train \#22 
experienced a 2 hour, 45 minute delay between Riverside and Colton Crossing. Evidently there were unknown disruptions (e.g., trackside detector alarms, pickups or setouts, change-out of locomotives, etc.) impacting these two train movements. Such disruptions were not included in the simulation runs. Thus, another simulation run and comparison were started over after deleting these two trains.

Considering the 23 BNSF trains (the Trains \#19 and \#22 were removed), statistics on actual and simulated transit time are displayed in Table 4. After removal of outliers, the statistics on actual and simulated trains were remarkably close.

\section{<insert Table 4 here>}

\section{Interpretations of Simulation Outputs}

The simulated running time with no delay for the BNSF MAERSK double-stack container trains between Long Beach Junction and Colton Crossing was about 2 hours, 21 minutes. This was generated by running the simulation with only one train in the model. There would be no wait time or delay, since there was only one train running on the railroads. The minimum actual EDI-reported running time between these points was 2 hours, 10 minutes. Evidently, actual train movements sometimes experienced almost no delay, and they sometimes exceeded the official railroad speed limits imposed in the simulation. The speed of a train operating with a clear signal was ultimately up to the locomotive engineer. Exceeding posted speed limits by five miles per hour was common practice on some railroads, especially on the tangent track away from terminals. In contrast, the best simulated transit time was 2 hours, 27 minutes. At the other extreme, both the simulated and actual maximum transit times were about 5 hours, indicating that delays sometimes amounted to more than two and one-half hours.

\section{Analysis of Congestions and Delays}

To exercise the analytical abilities of the simulation model, this study analyzed the delays experienced by these trains. Bottlenecks, i.e., points with high frequency and significant duration of delay, were identified and tabulated. The statistics on probabilities and durations of delay for the $23 \mathrm{BNSF}$ train movements are displayed in rank order of impact in Table 5.

\section{<insert Table 5 here>}

As seen in Table 5, delays along the BNSF main line Hobart - Colton Crossing in aggregate were more significant than delays in the Alameda Corridor. This was because all trains in the Corridor operated at comparable speeds with comparable priorities, whereas the BNSF main line hosted a variety of train types operating at various speeds and with varying priorities. Moreover, there were major junctions along the BNSF main line where traffic must merge/diverge at grade.

The worst delay point was Riverside, with more than 50 percent of the container trains getting stopped there. This impact was in line with an earlier study [12], which proposed re-routing the UPRR freight traffic off the BNSF main line through Riverside and on the UPRR main line via West Colton. The next worst impact was Arlington, with more than 25 percent getting stopped. Most of these delays were because another train was stopped ahead at Riverside. That was why both Arlington and Riverside delays reflected the capacity bottleneck at Riverside.

The Riverside bottleneck had several causes. First, many METROLINK commuter trains originated and terminated here. Second, considerable UPRR freight traffic utilized the BNSF main line Riverside Colton Crossing and must merge/diverge here.

Delays at Fullerton were the next worst, where Amtrak and METROLINK trains operating To/From San Diego Line interfered with East-West freight movements. Forty-three percent of the container trains stopped here. Delays at Buena Park, La Mirada, DT Junction and Commerce were related to heavy Amtrak passenger and METROLINK commuter train movements on the two-main-track segment [13].

\section{STATISTICAL VALIDATION OF TRAIN SIMULATION MODEL}

To validate the simulation model by statistical tests, the simulated transit times between Long Beach Junction and Colton Crossing were used to compare with the actual transit times between these points.

\section{First Hypothesis Test on the Averages of Transit Flow Time}

The transit flow time of two small samples with equal sizes of 23 were collected from actual train runs and simulation train runs separately. Both average flow time populations were assumed to be normal distribution, and population variances were unknown. Therefore, the two-sample t-test was appropriate to 
test $\mathrm{H}_{0}$ with a level of significance 0.05 as follows [30]:

$\mathrm{H}_{0}$ : There is no difference in the averages of transit flow time between actual trains and simulation trains.

$\mathrm{H}_{1}$ : The actual trains and simulation trains differ in the averages of transit flow time.

\section{Statistical Test}

The sampling values were approximated by $t$ distribution with degrees of freedom and sample means calculated as follows:

$d f_{1}=\left(n_{1}-1\right)=22$, and $d f_{2}=\left(n_{2}-1\right)=22$.

$X_{1}=206$, and $X_{2}=208$.

$s_{p}=\operatorname{SQRT}\left[\left(\left(n_{1}-1\right) s_{1}{ }^{2}+\left(n_{2}-1\right) s_{2}{ }^{2}\right) /\left(n_{1}+n_{2}-2\right)\right]$

$=47.17$,

$t=\left(X_{1}-X_{2}\right) /\left(s_{p^{*}} \operatorname{SQRT}\left(1 / n_{1+} 1 / n_{2}\right)\right)=-0.1438$.

\section{Decision}

The region of rejection indicated that the critical value, for $\mathrm{t}(0.025,22)$, was -2.0739 . The observed value of $t,-0.1438$, did not exceed -2.0739 . Therefore, this study failed to reject the null hypothesis and concluded that there was no difference in the averages of transit flow time between actual trains and simulation trains. The model was reliable under the assumptions.

\section{Second Hypothesis Test on the Variation of Train Flow Time}

This study conducted a second Hypothesis Test to compare two population variances by using the $\mathrm{F}$ distribution [30]:

$\mathrm{H}_{0}$ : There is no difference in the variation of transit flow time between actual trains and simulation trains.

$\mathrm{H}_{1}$ : The actual trains and simulation trains differ in the variation of transit flow time.

\section{Statistical Test}

The sampling distribution of $F$ values were approximated by $\mathrm{F}$ distribution with degrees of freedom and sample standard deviations calculated as follows:

$d f_{1}=\left(n_{1}-1\right)=22$, and $d f_{2}=\left(n_{2}-1\right)=22$.

$s_{1}=43$, and $s_{2}=51$.

$F=s_{2}^{2} / s_{1}^{2}=1.186$.

\section{Decision}

The region of rejection consisted of those $\mathrm{F}$ values that exceeded the critical value, $F(0.025,22,22)=$ 2.36. The observed value of $\mathrm{F}, 1.186$, did not exceed 2.36. Therefore, this study failed to reject the null hypothesis and concluded that there was no difference in the variation of transit flow time between actual trains and simulation trains. Again, the model was reliable under the assumptions.

\section{CONCLUSIONS, RECOMMENDATIONS, AND IMPLICATIONS}

\section{Forecast Tools of Dispatching Simulation Model}

The mean and standard deviation statistics on the EDI/RFID/AEI-generated transit time from $23 \mathrm{BNSF}$ trains between Long Beach Junction and Colton Crossing matched the respective statistics of simulated train movements within single-digit numbers of minutes. In other words, the results of this test indicate that this rail dispatching simulation model is statistically reliable as an analytical and predictive tool. In more congested and volatile situations with more inherent variability, a larger number of simulated movements would be required to establish accurate statistical distributions [13].

This simulation model allows each computer run to be uniquely defined in various levels of the volume, track resource capacity, and statistical variables. Specifically, the user can specify volumes of traffic for any of these input file combinations. This approach supports the objective of creating a higher level model that can represent scenarios from existing Southern California operations to futuristic scenarios of other port complex.

\section{Real-time Access Using $\mathrm{KSCN}$ and Intelligent Databases}

Furthermore, the proposed $\mathrm{KSCN}$ has presented a methodology to manage the information flows via a database design using essential messages. This research captures primary keys and data elements from deployment shipments and EDI messages as a medium to generate standardized information traffic. It also incorporates inputs from the RFID, AEI tags, and receivers to track down containers movements through the KSCN [27]. This study emphasizes that the real-time application of the simulation model is feasible and practical for the goods movement in the supply chains. 


\section{From Conventional Railway to Maglev or High} Speed Trains

The KSCN and simulation model could be expanded to analyze future operating scenarios (maglev applications) to demonstrate efficient marine terminal loading and volume shipments organization as follows $[14,18]$ :

(1) Mega ship with pre-sorting of containers at the port of embarkation.

(2) Mega ship with post-sorting of containers at the port of debarkation.

(3) Live loading/direct vessel transfer of trains and double cycling of containers.

(4) Maximum use of shuttle trains with sorting by destinations at inland hub facility.

In summary, the future plans of container shipments lie in the automation of the loading and transporting of railcar compartments that hold multiple containers and fly on a magnetic track at high speeds. The AirRail concept is to utilize fully automated loading of magnetic levitation vehicles that hold up to 16 containers in each maglev compartment, and are able to transport hundreds of modules at a time [1]. For the containers that leave the marine terminal via maglev rails, it is also required to utilize a larger maglev buffer storage area where groups of maglev platforms are consolidated into a shuttle (train) trip for departure via the maglev corridor [24].

\section{APPENDIX}

\section{Authentication and Acknowledgement}

The authors would like to extend gratitude to Dr. Robert C. Leachman, University of California, Berkeley. He helped certify that the simulation results reported herein were valid.

\section{REFERENCES}

1. Bonsor, K. (2010). How Maglev Trains Work. Available http://www.howstuffworks.com/maglevtrain.htm.

2. Chen, A. L. Mallon, and J. Hwang, (2005). Military and Commercial Agile Supply Network Optimization and Security, Phase I. Working paper, Center for the Commercial Deployment of Transportation Technologies, California State University, Long Beach.

3. Chen, A. L. Mallon, and J. Hwang, (2006). Military and Commercial Agile Supply Network
Optimization and Security Operational Concept Document Annex D: Rail Agile Port Network Model Integration Plan Technical Report, Phase IV. Working paper, Center for The Commercial Deployment of Transportation Technologies, California State University, Long Beach.

4. Chen, A. L. Mallon, and J. Hwang, (2007). Military and Commercial Agile Supply Network Optimization and Security: A Database Design Application Using Electronic Data Interchange, Automatic Equipment Identification, and Radio Frequency Identification Messages in Southern California. Proceedings of IACIS Pacific 2005 International Conference on RFID and Mobile Communications, Taipei, ROC.

5. Chen, A. (2010). Maglev. Available at: http://secureworldtrade.com/index.php?option $=\mathrm{c}$ om content\&view=section\&layout=blog \&id=2\&Itemid $=98$.

6. Hwang, J., A. Chen, and L. Mallon. (2004). Database Development with Electronic Data Interchange for Regional Supply Chain Simulation (RSCS): An Application to Freight Movement in Southern California, Proceedings of $2^{\text {nd }}$ International Conference on Business, Economics, Management \& Marketing, Athens Institute for Education and Research, Athens, Greece.

7. Hwang, J., and L. Mallon. (2004). Regional Supply Chain Simulation (RSCS): Application of an Extensible, Modular Approach to Goods Movement Performance Measurement in Southern California, Proceedings of $83^{\text {rd }}$ Annual Conference of Transportation Research Board, National Academies, Washington, DC.

8. Hwang, J.D. and Le, D.H. (2003). Collaborative Goods Movement in Southern California: Information Technology for Supply Chain Management. Proceedings, $8^{\text {th }}$ Internationa Computer Conference on Urban Policy and Urban Management. Sendai, Japan.

9. Leachman and Associates. (1984). San Pedro Bay Ports Access Study, Phase I. Railroad Access, Volume II - Railroad Operations Analysis. Prepared for the Southern California Association of Governments (SCAG), the Port of Long Beach and the Port of Los Angeles.

10. Leachman and Associates. (1984). San Pedro Bay Ports Access Study, Phase II. Railroad Access, Volume II - Railroad Operations Analysis. Prepared for the Southern California Association of Governments (SCAG), the Port of Long Beach and the Port of Los Angeles. 
11. Leachman and Associates. (1991). Railroad Capacity and Operations Analysis for the Alameda Consolidated Transportation Corridor Project. Working paper prepared for the Alameda Corridor Transportation Authority while acting as a sub consultant to DMJM, Inc.

12. Leachman and Associates, Los Angeles Economic Development Corporation. (2002). Los Angeles-Inland Empire Railroad Main Line Advanced Planning Study. Working paper prepared for the Southern California Association of Governments (SCAG).

13. Leachman and Associates, and M. Dessouky. (2007). Rail Network Capacity Analysis: Military and Commercial Facility Use Strategic Assessment Technical Report - An Integrated Approach to Managing Local Container Traffic Growth in Long Beach-Los Angeles Port Complex, Phase II. Working paper, University of California, Berkeley.

14. Lloyd, G. (2010). Mega Container Carrier. Available at http://www.marinetalk.com/articlesmarine-companies/art/Mega-Container-CarrierGER022102610TU.html.

15. Mallon, L. (2003). Optimization of Military and Commercial Goods Movement Through Southern California Using Information Technology, Phase 1. Speech delivered at California State University, Long Beach.

16. Mallon, L., and J. Hwang. (2003). Optimization of Military and Commercial Goods Movement Through Southern California Using Information Technology, Phase 2. Speech delivered At California State University, Long Beach.

17. Mallon, L., and Hwang, J. (2002). Southern California Regional Supply Chain Simulation Model, Proceedings, First International Conference on Information and Management Sciences, Xian, China.

18. Mallon, L., Hwang, J., and Hale, B. (2001). Discussion of: High Speed Surface Ocean Transportation and Supply Chain Agility. Center for International Trade and Transportation, California State University, Long Beach.

19. Magaddino, J., and Mallon, L. (2001). An Integrated Approach to Managing Local Container Traffic Growth in Long Beach-Los Angeles Port Complex, Phase II. Working paper, California State University, Long Beach.
20. Mehlberg, Udo. (1974). Discussion of: Container Ship Loading/Unloading and Intermodal Operation in Taichung Port Complex. Working paper, Ten Major Construction Projects, Taiwan, the Republic of China.

21. Mehlberg, Udo. (2005). Discussion of: Marine Terminal Server: Vessel berths, On-Dock Intermodal Rail, and Gate Operations. Working paper, University of California, Berkeley.

22. Pritsker, A. (1984). Simulation and SLAM II. New York: Wiley \& Sons.

23. Pritsker, A., and O'Reilly, J. (1999). Simulation with Visual SLAM and Awesim. New York: Wiley \& Sons.

24. Quain, J. (2010). Super Trains: Plans to Fix US Rail Could End Road and Sky Gridlock. PopularMechanics. Available at http://www.popularmechanics.com/technology/e ngineering/infrastructure/4232548.

25. Shannon, R. E. and W. E. Biles. (1970). The Utility of Certain Curriculum Topics to Operations Research Practitioners. Operation Research. Vol. 18: 741-745.

26. Stadtler, H., and Kilger, C. (2000). Supply Chain Management and Advanced Planning. Boston: Springer.

27. Swedberg, C. (2010). Royal Freight Expects Trailer-Tracking System to Yield Greater Security. RFID Journal. Available at http://www.rfidjournal.com/article/view/7489.

28. Turban, E. (1972). A Sample Survey of Operations Research Activities at the Corporate Level. Operation Research. Vol. 20: 708-721.

29. Weaton, A. (1984). Systems Simulation: The Art and Science. New York: Prentice-Hall. XML/EDI Group. 1998. Guidelines for Using XML for Electronic Data Interchange. Available at http://www.xmledigroup.org/xmledigroup/guide.htm.

30. Wollmer, R. and L. Chao. (2001). Statistics for Management. Los Angeles: Wiley \& sons. 


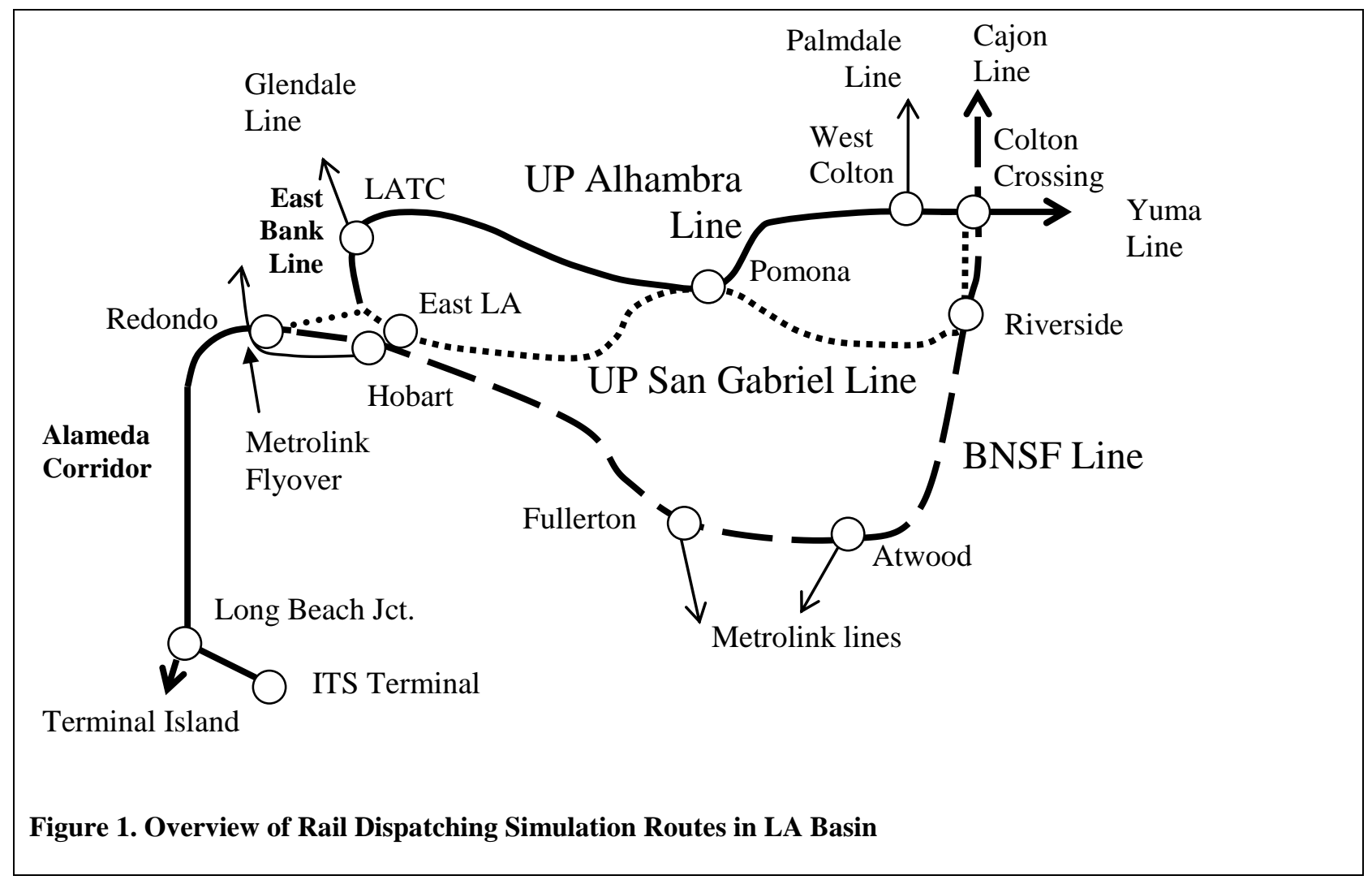

Table 1. UMLER Data

\begin{tabular}{|l|l|l|l|l|}
\hline & UMLER Field Name & Position & Length & Description \\
\hline 1 & Mark & $1-4$ & 4 & Alpha mark of car \\
\hline 2 & Number & $5-10$ & 6 & Numeric of car \\
\hline 3 & Articulated Count & $11-12$ & 2 & Number of platforms in set \\
\hline 4 & Articulated Code & $13-14$ & 2 & Articulated only \\
\hline 5 & Equipment Type Code & $15-18$ & 4 & For articulated, type is one position \\
\hline 6 & Outside Length & $19-23$ & 5 & Base only \\
\hline 7 & Platform Length & $24-27$ & 4 & \\
\hline 8 & Platform Width & $28-31$ & 4 & Base only \\
\hline 9 & Bulkhead Height & $32-35$ & 4 & Base only \\
\hline 10 & Tare Weight & $36-39$ & 4 & \\
\hline 11 & Load Limit & $40-43$ & 4 & \\
\hline 12 & Trailer Capacity Code & $44-45$ & 2 & Articulated only \\
\hline 13 & Container Capacity Code & $46-47$ & 2 & Articulated only \\
\hline 14 & Axles & $48-49$ & 2 & Base only \\
\hline
\end{tabular}


Table 2. AEI Header Example and Record Layout (T94 Format)

TA75634 20071019 1019 1040 080 Y 412 8452 G A S S D E 010 000 008 C N F N N05303 G 01 01 0 23 023 228270001

\begin{tabular}{|l|l|l|l|l|l|}
\hline$\underline{\text { Order }}$ & Field Names & $\underline{\text { Order }}$ & Field Names & $\underline{\text { Order }}$ & Field Names \\
\hline 1 & Site ID & 10 & Car status & 19 & Transmission type \\
\hline 2 & Event start date & 11 & Direction of travel & 20 & Adj. track occupied \\
\hline 3 & Event start time & 12 & Switch direction & 21 & Train length \\
\hline 4 & Event stop time & 13 & Unit of measure & 22 & Equipment status \\
\hline 5 & Time zone & 14 & Max train speed & 23 & Total locomotives \\
\hline 6 & Daylight savings indicator & 15 & Min train speed & 24 & Tagged locomotives \\
\hline 7 & Data format version & 16 & Average train speed & 25 & Total equipment \\
\hline 8 & Train Sequence & 17 & Train movement type & 26 & Tagged equipment \\
\hline 9 & Locomotive status & 18 & Termination status & 27 & TCN \\
\hline
\end{tabular}

Table 3. Actual vs. Simulated Transit Time

Long Beach Junction - Colton Crossing (Before Removing Outliers)

\begin{tabular}{llc} 
Statistics & Actual Movements & Simulated Movements \\
\hline Mean & 4 hours, 06 minutes & 3 hours, 20 minutes \\
Standard deviation & 1 hour, 12 minutes & 0 hours, 47 minutes \\
Minimum & 2 hours, 10 minutes & 2 hours, 27 minutes \\
Maximum & 6 hours, 54 minutes & 4 hours, 49 minutes \\
\hline
\end{tabular}

Table 4. Actual vs. Simulated Transit Time

Long Beach Junction - Colton Crossing (After Removing Outliers)

\begin{tabular}{lll} 
Statistics & Actual Movements & Simulated Movements \\
\hline Mean & 3 hours, 26 minutes & 3 hours, 28 minutes \\
Standard deviation & 0 hours, 43 minutes & 0 hours, 51 minutes \\
Minimum & 2 hours, 10 minutes & 2 hours, 27 minutes \\
Maximum & 4 hours, 53 minutes & 5 hours, 01 minutes \\
\hline
\end{tabular}

Table 5. Frequencies and Durations of Dispatching Delays (Long Beach Junction - Colton Crossing)

$\begin{array}{lccc}\text { Points of delay } & \begin{array}{c}\text { Avg. Wait Time } \\ \text { (Minutes) }\end{array} & \begin{array}{c}\text { Probability } \\ \text { of Stop }\end{array} & \begin{array}{c}\text { Delay Impact } \\ \text { (Probability*Wait Time) }\end{array} \\ \text { Riverside } & 18.21 & 0.53 & 9.71 \\ \text { Arlington } & 15.07 & 0.26 & 3.93 \\ \text { Fullerton } & 5.46 & 0.43 & 2.34 \\ \text { La Mirada } & 3.62 & 0.27 & 0.97 \\ \text { Colton Crossing } & 5.15 & 0.13 & 0.67 \\ \text { Commerce } & 2.78 & 0.22 & 0.62 \\ \text { DT Junction } & 3.34 & 0.13 & 0.44 \\ \text { Buena Park } & 3.16 & 0.11 & 0.33 \\ \text { CP West Redondo } & 5.01 & 0.06 & 0.30 \\ \text { CP Del Amo } & 2.36 & 0.08 & 0.18 \\ \text { Long Beach Junction } & 2.33 & 0.07 & 0.15 \\ \text { Hobart } & 1.91 & 0.05 & 0.10\end{array}$

